\title{
Algunos rasgos de la ontología de la historia propuesta por Bernhard Welte y sus desafíos para la teología
}

\author{
Joaquin Silva Soler \\ PONTIFICIA UNIVERSIDAD CATÓLICA DE CHILE \\ FACULTAD DE TEOLOGÍA
}

\section{Introducción}

La cuestión de la historia ocupó un lugar central en el pensamiento de B. Welte. En cada una de las cuatro décadas durante las cuales desarrolló su actividad intelectual dedicó al menos un texto importante a pensar la historia. El primero de estos textos -que permaneció inédito hasta hace pocos años- lo escribió cuando iniciaba su carrera académica, en Freiburg, con ocasión de sus lecciones del semestre de invierno de 1949$1950^{1}$. Ya en este texto expresa el interés filosófico que guiará todo su pensamiento respecto de la historia: proponer una «ontología de la historia», que contribuya a reconocer la esencia de aquello que llamamos historia, que permita escudriñar el ser mismo del tiempo, y que nos acerque a una comprensión más sustantiva del cristianismo ${ }^{2}$. Al poco tiempo de haber dictado estas lecciones, con ocasión de una conferencia ofrecida a profesores de filosofía y teología en París, publicó el año 1952, en la revista Saeculum, un artículo cuya temática estaría directamente asociada a la anterior y que seguiría pensando durante toda su vida: aquella de la relación entre verdad e historicidad ${ }^{3}$. Diez años más tarde, durante el semestre de verano del año 62, dedica todo un semestre a esta misma

1 B. Welte, «Geschichtlichkeit als Grundbestimmung des Christentums». Este texto ha sido publicado por primera vez el año 2006, con ocasión de la edición de sus obras completas: B. WeLte, Gesammelte Schriften. I/2: Mensch und Geschichte (Freiburg 2006) 136-274.

2 B. WeLte, Geschichtlichkeit als Grundbestimmung..., GS I/2, 150.

3 B. Welte, «Wahrheit und Geschichtlichkeit» en Saeculum 3 (1952) 177-191. En sus obras completas: B. WeLte, Gesammelte Schriften. I/2: Mensch und Geschichte (Freiburg 2006) 69-86. 
cuestión ${ }^{4}$. A los pocos años, durante el semestre de invierno 67-68, dicta un curso sobre historicidad y revelación ${ }^{5}$. En los años 70 publicará dos artículos: uno en el que propone una reflexión sobre el tiempo ${ }^{6}$ y otro en el que muestra el nexo entre experiencia e historia ${ }^{7}$. Por último, dos años antes de su muerte, el año 81, publica un texto en el que retoma esta cuestión que lo ha acompañado desde sus primeros escritos: la pregunta por la relación entre verdad e historia ${ }^{8}$. A diferencia de los textos anteriores, sin embargo, aquí introduce un elemento que hasta entonces solo había sido parcialmente considerado: el lenguaje, considerado este no solo como aquella dimensión humana donde se expresa y realiza el encuentro entre verdad e historia, sino que, al mismo tiempo, orienta este análisis a una consideración crítica del lenguaje en la Iglesia.

Ahora bien, la pregunta por el carácter teológico de la historia y la pregunta por el carácter histórico de la teología se compenetran y son coextensivas en el tiempo. Ya el año 1950 Welte escribe un artículo en la revista de la Facultad de Tübingen sobre los modos concretos en que la situación epocal está marcando la comprensión y desarrollo de la teología, especialmente de la teología fundamental ${ }^{9}$. Cuatro años más tarde demuestra cómo

4 B. WeLte, «Wahrheit und Geschichtlichkeit». Estas lecciones del año 1962 fueron publicadas primero por Ingeborg Feige (B. WeLte, Wabrheit und Geschichtlichkeit. Zwei Vorlesungen, aus dem Machlass [Frankfurt a.M. 1996] 167-246) y recientemente en sus obras completas: B. WeLte, Gesammelte Schriften. I/ 2: Mensch und Geschichte, 87-135.

5 B. Welte, «Geschichtlichkeit und Offenbarung». Estas lecciones fueron publicadas por primera vez el año 1993, diez años después de la muerte de Welte, por BERNhard Casper e Ingeborg Feige (eds.), Geschichtlichkeit und Offenbarung (Frankfurt a.M. 1993) 19-169. Recientemente, el texto ha sido revisado y se ha vuelto a publicar con ocasión de la edición de las obras completas, en: B. WeLTE, Gesammelte Schriften. I/2: Mensch und Geschichte, 275-350.

6 B. WeLte, «Meditation über die Zeit», en Tübinger Theologische Quartalschrift 151 (1971) 289-299. En sus obras completas: B. Welte, Gesammelte Schriften. I/2: Mensch und Geschichte, 19-31.

7 B. Welte, «Erfahrung und Geschichte», en Wort und Wabrheit 25 (1970) 145-153. En sus obras completas: B. WeLte, Gesammelte Schriften. I/ 2: Mensch und Geschichte, 32-45.

8 B. Welte, «Wahrheit, Sprache und Geschichte - Untersucht im Blick auf die Sprache in der Kirche», en: H. Fries - K. RAHNer (eds.), Theologie in Freiheit und Verantwortung (München 1981) 70-95. Un año más tarde, esre tecto fue publicado por el mismo B. Welte, en su libro Zwischen Zeit und Ewigkeit. Abhandlungen und Versuche (Freiburg 1982) 211-232. Recientemente publicado en: B. Welte, Gesammelte Schriften. I/2: Mensch und Geschichte, 46-68.

9 «Zur geistesgeschichtlichen Lage der Fundamentaltheologie», en Theologische Quartalschrift 130 (1950) 385-406. Texto que luego fue publicado bajo el título «Zur Lage der Fundamentaltheologie heute», en: B. Welte, Auf der spur des Ewigen: Philsophische 
el siglo XIX constituye un momento particularmente decisivo para la autocomprensión de la teología ${ }^{10}$. Al año siguiente, 1955, como Rector de la Universidad de Freiburg, dicta una conferencia en la que trata la cuestión del estatuto epistemológico de la teología y, especialmente, de su relación con las demás disciplinas ${ }^{11}$. Esta será también una ocasión para mostrar cómo la historicidad del pensamiento teológico no va en desmedro de su cientificidad sino que la determina internamente. La cuestión alcanza, a nuestro juicio, un momento decisivo cuando Welte expresamente aborda la relación entre filosofía y teología, puesto que esto no lo hace en abstracto, sino que, justamente, reconociendo que ambos modos de conocer la verdad se implican mutuamente por su relación a la historia ${ }^{12}$.

Años más tarde, en un libro en homenaje a Karl Rahner, el filósofo de Freiburg propone una consideración del método de la teología en la que vuelve a hacer patente aquella mutua referencia entre teología e historia ${ }^{13}$. En 1974, la celebración de los 700 años del nacimiento de Tomás de Aquino ofrece a Welte una excelente ocasión para ahora pensar esta relación entre historia y teología en relación a uno de los testimonios mayores de un pensamiento teológico capaz de asumir con audacia y prudencia los desafíos de su tiempo ${ }^{14}$. El mismo año 74 el filósofo y teólogo de Freiburg vuelve sobre una cuestión que casi veinte años antes ya había tratado, pero que entre tanto se había constituido en una pregunta que determinaba su propio quehacer intelectual: la cuestión del implicado filosófico en el

Abhandlugen über verschiedene Gegenstände der Religion und der Theologie (Freiburg 1965) 297-314.

10 «Zum Strukturwandel der katholischen Theologie im 19. Jahrhundert», en: C. BAuER y otros, Gestaltende Kräfte im 19. Jahrbundert (Freiburg 1954) 25-55. Este texto se volvió a publicar en: B. Welte, Auf der Spur des Ewigen..., op. cit., 380-409.

11 Die Wesensstruktur der Theologie als Wissenschaft. Freiburger Rektoratsrede am 14. Mai 1955, (Freiburg 1955). El tecto fue reeditado en: B. Welte, Auf der Spur des Ewigen..., op. cit., 351-365.

12 «Die Philosophie in der Theologie» en: Die Albert-Ludwigs-Universität 1457-1957 (Freiburg 1957), 27-41. Luego en: B. Welte, Auf der Spur des Ewigen..., op. cit., 366-379.

13 «Ein Vorschlag zur Methode der Theologie heute», en: J. B. MeTz (ed.), Gott in Welt. Festschrift für Karl Rahner (Freiburg 1964) 271-286. Se volvió a publicar en: B. Welte, Auf der Spur des Emigen..., op. cit., 410-426.

14 «Mut und Besonnenheit. Der Denktyp des Thomas von Aquin, dargestellt an seiner Stellung im Streit um den Aristotelismus in der Theologie», Theologisch-praktische Quartalschrift 122 (1974) 313-324. Publicado luego bajo el título: «Thomas von Aquin und der Streit um den Aristotelismus. Oder: Mut und Besonnenheit. Zum 700. Geburtstag von Thomas von Aquin» en: B. Welte, Zeit und Geheimnis, 1975, 181-202. 
quehacer teológico ${ }^{15}$. Por cierto, esta no era solo una cuestión de epistemología teológica, sino que -más fundamentalmente- en ella nuevamente se manifestaba la pregunta por las condiciones históricas en las que se constituye relacionalmente todo pensamiento. Profundizando en esta línea de investigación, al año siguiente Welte recurre a otro gran filósofo -a Friedrich Hegel- para reflexionar acerca de esta textura histórica del pensamiento. Aquí no solo considera el aporte de Hegel en su contexto histórico inmediato, sino que especialmente encuentra en él impulsos para pensar teológicamente nuestra propia historia ${ }^{16}$. En esta misma década del 70 -lejos, para él, la más productiva intelectualmente-, Welte aborda esta cuestión de la relación historia y teología desde una historia muy particular: la de Jesús de Nazareth ${ }^{17}$. En efecto, la pregunta de fondo que subyace a este escrito de carácter más cristológico es cómo este acontecimiento singular, la historia de Jesús de Nazareth, se constituye en acontecimiento universal de salvación, determinando internamente así no solo el pensamiento teológico, sino que todo pensar.

Condicionado por las mismas circunstancias históricas, el año 1980 Bernhard Welte decide tomar partido en torno al caso Hans Küng y escribe un breve artículo, en el que propone discutir la cuestión de la infalibilidad en relación a la comprensión misma de la verdad, puesto que -en su opinión- «gran parte de la controversia y de los malentendidos de H. Küng y de sus adversarios -intra y extraeclesiales- descansa en un concepto de verdad unidimensional y no suficientemente explicitado o explícito» ${ }^{18}$. En la explicitación del concepto de verdad le interesa demostrar cómo «lo que llamamos verdad es una magnitud que no está inequívocamente establecida» ${ }^{19}$.

15 «Was hat die Philosophie in der Theologie zu tun?», en Theologische Quartalschrift 154 (1974) 303-310.

16 «Hegels theologischer Entwurf als Ausdruck einer geschichtlichen Situation und als Impuls einer neuen Geschichte der Theologie», en: G. Schwanger (ed.), Kirche und Theologie im 19. Jahrbundert (Göttingen 1975) 137-146. Vuelto a publicar en: Zeit und Geheimnis. Philosophische Abhandlungen zur Sache Gottes in der Zeit der Welt (Freiburg 1975) 228-240.

17 «Jesus Christus und die Theologie», en: J. SAuER (ed.), Wer ist Jesus Christus? (Freiburg 1977) 151-164. Texto también publicado en: G. Picht - E. Rudolph (eds.), Theologie, was ist das? (Kreuz, Stuttgart 1977) 323-339.

18 «Die philosophisch-theologische Problematik», en Herderkorrespondenz 34 (1980) 7781. Traducción al español: «La problemática filosófico-teológica de la controversia en torno a H. Küng» en Seleciones de teología 77 (1981) 58-63.

19 Subrayado en el texto. Adicionalmente, en el sentido de Welte, habría que subrayar especialmente la expresión «lo que llamamos», puesto que -como diremos más adelante- no se trata de claudicar ante la cuestión de la verdad, sino que de establecer su historicidad en el acontecer del lenguaje. 
En esta misma perspectiva, dos años más tarde, Welte vuelve a un diagnóstico crítico sobre la teología y profundiza sobre aquella propuesta que ya había formulado en repetidas ocasiones, en orden a reconocer el implicado filosófico del mismo quehacer teológico ${ }^{20}$; implicado que es requerido por el desarrollo interno de la misma teología, pero que -a su vez- está exigido por la misma textura histórica de su despliegue en la historia.

Escapa a las posibilidades de este texto dar cuenta de todos estos escritos de Welte. Más bien, en continuidad con otros trabajos que he realizado sobre el autor ${ }^{21}$, queremos ahora caracterizar en sus rasgos más generales aquello que en aquel texto de 1950 Welte denomina «ontología de la historia». Desde este texto, recién publicado el año 2006, queremos esbozar los rasgos fundamentales de la ontología de la historia propuesta por Welte a lo largo de su trayectoria filosófica. De este modo, Geschichtlichkeit als Grundbestimmung des Christentums nos servirá como impulso inicial y como guía de nuestras propias reflexiones, sobre todo en orden a reconocer los desafíos que representa para la teología el reconocer la historia como determinación fundamental de nuestra condición humana y, por tanto, también teológica. La complejidad del tema, la profundidad con que el autor lo estudia, la variedad de textos en que ello lo hace y, por cierto, nuestras propias limitaciones, nos hacen ser cautos con lo que aquí prometemos y, por ello, solo nos atrevemos a hablar de algunos rasgos de la ontología de la historia propuesta por Welte. Con todo, consideramos que ya estos rasgos representan una invitación para seguir pensando a Dios en las condiciones concretas de nuestro tiempo.

\section{Rasgos de una ontología de la historia}

\section{La bistoria como realización de la libertad}

La historia, afirma Welte, condiciona y determina toda realidad humana ${ }^{22}$. Pero esta determinación histórica de la condición humana, en su misma

20 «Zur Lage der Theologie heute und zur Rolle der Philosophie im Rahmen dieser Situation», en: B. CASPER (ed.) Die Angewiesenheit der Theologie auf das philosophische Fragen (München 1982) 65-70.

21 Especialmente hago mención a dos de ellos, por la cercanía que tienen con nuestra temática actual: «Den Glauben in der Konkretheit der Geschichte Denken. Bernhard Weltes Beiträge zur Theologie», en M. EскноLт (Ed.), "Clash of civilizations" - oder Begegnung der Kulturen aus dem Geist des Evangeliums?. Bernhard Weltes Impulse für den interkulturellen Dialog mit Lateinamerika (Berlin 2009) 51-67. J. SILVA, La verdadera religión: Un diálogo con Bernhard Welte (Universidad Católica del Maule: Colección Tabor $n^{\circ}$ 18, Talca 2000), especialmente las páginas 107-114.

22 B. WeLte, Geschichtlichkeit als Grundbestimmung..., GS I/2, 137. 
radicalidad, no constituye un postulado abstracto de carácter esencialista, sino que él mismo es histórico; es decir, se trata de un acontecimiento posibilitado por el ejercicio mismo de la libertad. Lo histórico no adviene a la realidad humana, no se adhiere a esta como una determinación extrínseca, ni siquiera es el descubrimiento de alguna dimensión olvidada de la existencia. La historia, más bien, acontece en el ejercicio mismo de la libertad. Es en el hombre, nunca fuera de él, donde historia y mundo llegan a ser lo que son. En el despliegue de su existencia histórica el hombre hace que el mundo sea para él efectivamente mundo. Sin el hombre y su despliegue histórico -explica Welte- el mundo no es mundo ${ }^{23}$.

Al pensar la historia, más aún la historicidad, se corre el peligro de pensar una generalidad, una abstracción, una ley universal. Incluso hablamos de procesos históricos como realidades autónomas. Por otra parte, está el riesgo de pensar la historia desde la sola particularidad e individualidad, como si estas historias fueran inconexas, fueran ellas también producto de la necesidad de leyes inmanentes a los sujetos. A nuestro entender, Welte propone una ontología de la historia en la que esta, sea en su consideración individual o colectiva, se inserta en la libertad personal, siendo así, en el fondo, una ontología de la libertad. No hay hechos individuales que puedan ser comprendidos como acontecimientos históricos, si ellos quedaran solo como hechos narrados y concatenados por postulados teóricos superpuestos a ellos, cuestión que muchas veces hace la historiografía (Historie) ${ }^{24}$. Pero tampoco hay acontecimiento histórico sin hechos individuales que los sostengan y conforme. Una historia sin hechos es una ilusión, quizás un deseo. Pero no solo se requieren hechos, se requieren que esos hechos sean reconocidos e interpretados desde la libertad del sujeto. De este modo, sin ejercicio de la libertad no hay historia personal ni social, no hay auténtica acción, como diría Blondel ${ }^{25}$.

Lo anterior no significa que el hombre sea el hacedor, constructor o creador del mundo. Porque la historia justamente acontece como despliegue de la libertad, entonces la historicidad del hombre y del mundo no

23 B. WeLte, Geschichtlichkeit als Grundbestimmung..., GS I/2, 138.

24 Cf. B. WeLte, Geschichtlichkeit als Grundbestimmung..., GS I/2, 152.

25 BLondel piensa que las enseñanzas «necesitan ser comprendidas para ser vividas» (M. BLONDEL, La Acción (1893): Ensayo de una crítica de la vida y de una ciencia de la práctica, (Madrid 1996), 139. Cualquier intento por descartar el pensamiento resultaría contrario a las posibilidades mismas de vivir una historia con sentido. No se trata, por cierto, de crasos racionalismos, sino de reconocer que el comprender es una condición que posibilita la auténtica acción $\mathrm{y}$, por tanto, la libertad. 
es un en-sí, una realidad unívoca, un objeto reductible al poder del concepto. La irreductibilidad de la historia se expresa en el mismo preguntar del hombre. Si preguntamos es porque reconocemos una diferencia -al menos posible- entre lo que percibimos y lo que es; entre lo que es y lo que puede llegar a ser; entre lo que llega a ser y lo que podría haber sido, etc. Esta serie de diferencias en las cuales acontece la historia, nos remiten -sin embargo- a una unidad, a la unidad esencial de la libertad del sujeto que pregunta por el sentido esas diferencias.

\section{Originalidad e irreductibilidad de la bistoria}

En la perspectiva de la reflexión anterior hay que decir que la historia es acontecimiento de la libertad, no solo ni principalmente allí donde yo puedo comprender un hecho particular en relación a un concepto universal -cuestión que asemejaría la historia a la física ${ }^{26}$-, sino cuando el acontecimiento se muestra en su irreductibilidad, cuando ya no sabemos cómo nombrarlo, cuando las determinaciones hasta ahora conocidas no son suficientes para dar cuenta de lo que sucede. ¿No es eso lo que hoy nos sucede con nuestro propio tiempo histórico? ¿Cómo le llamamos: modernidad tardía, postmodernidad, globalización...? ¿Dan cuenta estos conceptos generales -o algún otro- de lo que hoy acontece? Pareciera que, justamente, la historia se muestra como historia cuando ella supera los estrechos márgenes de nuestros conceptos, ideas y esperanzas; cuando ella nos impulsa a abrirnos a su complejidad y nos hace reconocer nuestra perplejidad; cuando exige de nosotros un pensar creativo, que sepa conjugar la humildad con la audacia, que nos permita acercarnos con lucidez a aquello que en la historia también adviene como nuevo, como posibilidades inéditas para nuestro ser en el mundo. Esta interpelación de la historia a la libertad del pensar no siempre nos conducirá tan rápida e inmediatamente al concepto, habrá también que comprender que muchas veces la palabra más lúcida es la contemplación y el silencio. Esto no por flojera o cobardía del espíritu, como podría sospechar $\mathrm{Kant}^{27}$, sino por fidelidad histórica.

26 Como escribe Welte: «Die Geschichte als Wissen erhält dann die Struktur der Physik: Dies und dies is das (selbst geschichtslose) Wesen und Gesetz, das hier waltet, man sieht es an den un den Beispielen -Experimenten-, welche die Menschen selbst angestellt haben» (B. Welte, Geschichtlichkeit als Grundbestimmung..., GS I/2, 153).

27 «Faulheit und Feigheit sind die Ursachen, warum ein so großer Teil der Menschen, nachdem sie die Natur längst von fremder Leitung frei gesprochen (naturaliter ma- 
En el sentido anterior, lo histórico en cuanto acontecimiento de la libertad, no se deja deducir de un concepto general de carácter esencial; los acontecimientos históricos no son simples hechos particulares de un acontecer general; cada hecho -si es histórico- es porque desde él se expresa su propia originalidad, irrepetibilidad, irreductibilidad. Aunque estos hechos históricos estuviesen asociados a un origen superior, afirma Welte, ello nunca es en desmedro de cada suceso y acontecimiento particular ${ }^{28}$. Por tanto, no se trata de afirmar la particularidad -en su irreductibilidad y originalidad- en desmedro de la universalidad que pudiera expresarse en un concepto de carácter general, que, por ejemplo, apela a una época (modernidad, renacimiento, medioevo...) o a un sentido (progreso, liberación, salvación...). La cuestión es comprender que la afirmación de la particularidad, en su misma irrepetibilidad, está abierta a un sentido histórico mayor que el que le otorga su inmediatez; pero, a la vez, reconocer que ese sentido mayor no se constituye sino que en el acontecer de la particularidad. La historia acontece justamente en esta relación, nunca fuera de ella.

Cuando la unidad de la historia (época, sentido, o lo que sea) se afirma sin el reconocimiento de la particularidad, lo que normalmente se hace -la mayor de las veces, inconscientemente- es revestir de universalidad lo que no es sino particularidad. De allí que haya tantos que experimenten el olvidado de la historia, que quieran escribir «el reverso de la historia», que quieran decir su «historia no contada», etc. La historia, para ser tal, exige atraer a sí todo cuanto sucede. La particularidad, por insignificante que aparezca, o por relegada que esté, se resiste a la exclusión. Cada acontecer quiere ser reconocido en la historia, porque la historia requiere de cada acontecer.

\section{La apertura de la bistoria en su radical finitud e infinitud}

$\mathrm{El}$ acontecer histórico se muestra tanto en su finitud como en su infinitud. El no es solo su finitud, como tampoco es el postulado abstracto de alguna infinitud. Más bien, en su propio ser actual queda remitido a su ser posible y, con ello, a la infinitud de sus posibilidades pasadas, presentes y futuras.

Lo acontecido pudo no haber sido y, quizás, tenía más probabilidades de no haber sido. Lo mismo se puede decir del presente y del futuro. La misma concreción histórica se nos muestra en una apertura radical al ser.

iorennes), dennoch gerne zeitlebens unmündig bleiben» (I. KANT, Beantwortung der Frage: Was ist Aufklärung?).

28 Cf. B. Welte, Geschicbtlichkeit als Grundbestimmung..., GS I/2, 157. 
Sabemos que puede ser de otra manera a cómo es. En el caso de las personas, reconocemos una serie de conductas habituales y recurrentes, por ejemplo. Sin embargo, más allá de toda determinación, sabemos que podríamos llegar a ser diferentes, que podríamos, eventualmente, actuar distinto. En algunos casos, ello es fuente de esperanza, pero también pudiera causarnos temor. Lo predecible, por más que lo sea, puede sorprendernos.

Pero, al mismo tiempo, la relación finitud-infinitud de nuevo nos indica que ambos polos se requieren. Aquella apertura al ser más allá de toda factibilidad no es un mero postulado abstracto de carácter formal. Más bien, es la misma finitud del acontecer histórico, y justamente por ser acontecer histórico, la que nos remite a lo no acontecido, a lo no realizado plenamente, o, quizás, a lo adveniente.

Pero, lo adveniente no es solo esperanza; se cierne también como una amenaza radical. La apertura de la historia a sus múltiples posibilidades la sitúa a ella misma ante una posibilidad suprema y definitiva: la posibilidad de la muerte. La historia ya no acontece desde el no ser al ser, y en una de sus tantas concreciones posibles, sino que ahora tomamos conciencia de que aquello que acontece está radicalmente determinado por una posibilidad que niega toda otra concreción posible de la historia. Esta es la finitud radical de la historia, pero ya no en el juego de sus posibilidades de ser, sino en la provisoriedad de su acontecer, en la caducidad de sus logros, en la precariedad de sus realización. En último término, no solo sabemos que lo que es antes no era, sino también que aquello que es, dejará de serlo, y, quizás, para siempre.

De nuevo, ello no es un postulado abstracto, sino que estrictamente histórico. Es la misma historia la que nos manifiesta su provisoriedad, transitividad, caducidad. A pesar nuestro, hasta lo mejor del tiempo se desvanece, se debilita y muere: sic transit gloria mundi.

Pero también esta posibilidad suprema de la historia representa el fin de todo sufrimiento, de toda inequidad, de toda ignominia. De múltiples maneras, es el propio acontecer histórico el que nos muestra que la fugacidad del tiempo también puede alcanzar aquello contra lo cual luchamos y que, quizás, nunca lleguemos a vencer. Por tanto, esta provisoriedad de la historia no es solo amenaza de aquello que amamos, sino que también ella nos dice que lo dado no es la última palabra sobre el ser, que lo que vivimos será de todas maneras diferente, que no estamos condenados a soportar el mal que experimentamos. $\mathrm{Al}$ reconocer la historia en su provisoriedad ella se puede constituir así en fuente de esperanza, en afirmación lúcida de la vida que puede llegar a ser, en impulso a la acción. La finitud histórica no 
constituye, así, una mera realidad extrínseca al presente histórico, un acontecer futuro, un advenir, sino que está presente en las condiciones actuales de nuestra existencia personal y social. La finitud marca el acontecer actual, sea como esperanza o como amenaza; ella es una magnitud histórica actual; ella no está simplemente al final, sino que acompaña todo devenir histórico, otorgándole a este la impronta del acontecer de la libertad ${ }^{29}$.

Ahora bien, mientras más observamos la fugacidad del tiempo, mientras más experimentamos su finitud, mientras más patente se nos hace su provisoriedad, más acuciante se nos hace la pregunta por su significado ${ }^{30}$. Este ya no se sostiene, simplemente, en lo dado: en el concepto preconcebido, en la práctica consuetudinaria, o en la fortaleza de la voluntad. La provisoriedad de la existencia amenaza también todo concepto, práctica y propósito. Por tanto, esta provisoriedad exige revisar críticamente todo significado de la historia, no solo sometiéndolo al tribunal de la razón, sino que ahora también al tribunal de la radical finitud que representa la muerte. Es desde aquí que la pregunta por el sentido y el fundamento de cuanto es adquiere toda su seriedad, deja de ser un acertijo ingenuo y frívolo del porvenir, nos dispone a reconocer la consistencia de nuestra propia historia. Es así que la muerte, como propone Ignacio de Loyola, no es el simple corolario funesto o feliz de nuestros días, sino que puede ser también un criterio decisivo en el ejercicio de nuestra libertad ${ }^{31}$.

\section{La historia como despojamiento (Entrogenheit) y conservación (Behaltenheit)}

La dialéctica finitud-infinitud de la historia, explica B. Welte, comporta un doble movimiento: el despojar y el conservar ${ }^{32}$. Es despojamiento, por cuanto la finitud histórica -como está dicho- representa un desvanecer, marca un final, un dejar de ser. Sin embargo, especialmente cuando miramos hacia aquello que ha dejado de ser, es decir, cuando atendemos a la finitud ya acontecida, entonces percibimos que ella no ha sido, ni es, pura nada. Lo que ha sido es ahora contenido en nuestra conciencia de lo acon-

29 «Der Tod bestimmt wesentlich die ganze Seinart der geschichtlichen Zeitlichkeit» (B. Welte, Geschichtlichkeit als Grundbestimmung..., GS I/2, 171.

30 Cf. B. Welte, Geschichtlichkeit als Grundbestimmung..., GS I/2, 177 y ss.

31 Pensamos que es el sentido de la $3^{\text {a }}$ regla, del segundo modo, "para hacer sana y buena elección», propuesto por San Ignacio en los Ejercicios: «considerar como si estuviese en el artículo de la muerte, la forma y medida que entonces querría haber tenido en el modo de la presente elección, y reglándome por aquella, haga en todo la mi determinación» (Ej., 185).

32 Cf. B. WeLte, Gescbichtlichkeit als Grundbestimmung..., GS I/2, 162 y ss. 
tecido, de lo que ha dejado de ser, haciéndose ahora presente a nuestra mirada, a nuestro recuerdo, a nuestra memoria. Si ello simplemente hubiera sido, si no tuviéramos ninguna noticia de aquello que fue, entonces ello tampoco hubiera sido para nosotros, entonces tampoco hubiese habido despojamiento. Despojar y conservar se requieren mutuamente, son dos caras del acontecer de la historia, que contiene en el ser también aquello ha sido ${ }^{33}$.

En sus Meditaciones sobre el tiempo, Welte profundiza en esta misma estructura ontológica de la historia, pero ahora mostrando cómo la dinámica despojamiento-conservación puede ser puesta en movimiento por el pasado, por cuanto este puede ser reconocido como único futuro cierto de todo lo que es: «Se puede y debe decir: lo que ha sido en su poder secreto es el futuro de todo futuro. Porque este es el único futuro cierto de todo: el haber sido, este y solo este es el real e infalible porvenir» ${ }^{34}$. Pero así como el pasado que ha sido está contenido en el ser, el pasado que será, en su mismo despojamiento, también queda contenido el ser. Según explica el mismo Welte, «de cara a la caducidad, especialmente de cara a la muerte -la expresión más aguda y total de la caducidad-, nuestra naturaleza interna y nuestra comprensión original del ser nos dicen que ella realmente no debiera sen ${ }^{35}$. Incluso en las experiencias en las que la caducidad pudiera aparecer como algo deseable y con sentido, ella -en último término- se manifiesta como lo que no debe ser. Si en determinadas situaciones la misma muerte aparece como llena de sentido, como algo que debe ser, ello solo es posible desde una experiencia en la que el vivir aparece ya sin sentido y, así, la caducidad radical que representa la muerte se muestra como aquello que puede terminar con aquello que no debe ser; es decir, en la muerte se reconoce un sentido: ella puede terminar con esta vida que aparece como lo que no debe ser.

33 B. Welte explica esta conservación del ser de lo que ha sido mostrando cómo en el mismo lenguaje se construye la forma presente del perfecto: «Das Vergangene ist gewesen, es ist also» (B. WeLte, Geschichtlichkeit als Grundbestimmung..., GS I/2, 163). El ser contiene lo que ha sido.

34 B. Welte, «Meditation über Zeit», en: Zeit und Geheimnis, 21. Y más adelante escribe: «Der Abschied ins Gewesensein ist die einzig sichere Zukunft für alles; dafür ist offenbar gesorgt. Und so wartet das Gewesensein auf alles Zeitliche, um es aufzunehmen und versammeln und zu bewahren und niemals mehr herauszugeben. Es ist kein Ding, keine Substanz, kein Gegenstand». B. Welte, «Meditation über Zeit» en: Zeit und Geheimnis, 25-26 [cf. B. Welte, Geschichtlichkeit und Offenbarung, 50-59].

35 B. Welte, Heilsverständnis, 96. 
Ahora bien, determinante para una adecuada comprensión de esta dialéctica de despojamiento-conservación de la historia es la comprensión de su originalidad, cuestión que constituye más una obviedad teórica que una conciencia lúcida de la práctica. En efecto, podemos aceptar teóricamente que los hechos no se pueden repetir en la historia, sin embargo nos comportamos como si ello no fuera así, alterando de modo significativo nuestro modo de comportarnos en el tiempo. Aquellos hechos que nos han resultados más significativos procuramos repetirlos en el presente, pero al hacerlo terminamos sabiendo siempre que, tal vez, hoy puede ser semejante pero ya nunca igual. La conservación del tiempo pasado nunca es repetición o reiteración del hecho vivido. La presencia de lo acontecido abre siempre un espacio a la novedad del tiempo presente y queda abierta a lo impredecible del tiempo futuro. Por más que queramos reiterar el «tiempo pasado que fue mejor», el presente y el futuro nos dicen que ello ya nos es posible y que solo ese tiempo se podrá conservar en su apertura radical a lo nuevo, a lo inédito de todo tiempo. Hay despojamiento y conservación, pero la historia acontece como afirmación dinámica y relacional de ambos momentos.

Esta afirmación dinámica y relacional de la historia puede ser más o menos consciente en las personas, pero ella no acontece por la mera afirmación voluntarista de la personas. La irrepetibilidad de la historia nos dice, justamente, que querámoslo o no «lo que pasó, pasó». No hay nada que yo, o nosotros, podamos ahora hacer, para que ello no hubiese ocurrido. Como tampoco hay nada que nosotros podamos hacer, para que ello vuelva ocurrir, así como ya ocurrió. Tanto de lo que somos despojados como de aquello en lo que quedamos contenidos no son cosas que estén bajo nuestro dominio o poder, y poco importa si lo queremos o no. Lo que sí es necesario reconocer es cómo lo acontecido -más allá de nuestra voluntad- se despliega en la dinámica de la historia y le ofrece a esta las posibilidades de sus realizaciones futuras, no siendo nunca simple despojamiento ni simple conservación del pasado, haya sido este glorioso o funesto.

Cuando se produce aquel reconocimiento de la dinámica histórica entonces se abren posibilidades auténticas y reales a la libertad de las personas y de los pueblos. La libertad no es ya un ejercicio voluntarioso y antojadizo del deseo, sino que discernimiento real de las posibilidades de la acción, reconociendo cómo la historia no solo es testigo de lo que ha dejado de ser, sino que también en ella se contiene el ser de lo acontecido como posibilidades nuevas que es necesario recrear por medio del 
ejercicio de la libertad. Es ahora, entonces, cuando la libertad no queda sujeta al deseo, sino que ella se orienta por el ser que se le manifiesta en la historia. Esta, por su parte, deja de ser mera recopilación, más o menos pormenorizada, de hechos pasados, y adquiere por medio del ejercicio de la libertad toda su significación. Pero, de nuevo, esta donación de sentido que acontece en la libertad no es única ni definitiva. Acontecimientos del pasado que han sido conservados en el ser de la historia pueden en un tiempo volverse tremendamente significativos, pero al siguiente caer hasta casi en el olvido. El significado de la historia es el mismo histórico. No está determinado a priori, ni a posteriori. Se actualiza siempre por medio del ejercicio de la libertad.

Si la historia se nos muestra en esta dinámica de despojamiento y conservación, entonces, como ya se ha venido insinuando, esta estructura ontológica no queda referida solo a hechos del pasado y a sus posibles significados, sino que importa también a la comprensión de nuestro presente y futuro. La dinámica no caracteriza solo a un momento de la historia, o dimensión de ella, sino que expresa fenoménicamente una estructura que la afecta a toda ella. Y si es así, entonces reconocemos que aquello que llamamos presente histórico está generando las condiciones y posibilidades del futuro. De modo semejante a como hoy nosotros vivimos de condiciones y posibilidades del pasado -sin que podamos despojarnos de ellas y sin que podamos tampoco conservarlas-, así también el futuro se desplegará según los hechos y sucesos que hoy se establezcan como expresiones de nuestra acción en el mundo ${ }^{36}$. Por cierto, este fundamento actual del futuro no genera - para atrás ni para adelante- ningún tiempo de determinismo o secuencia mecánica del tipo causa-efecto. También el futuro, en su estructura ontológica histórica, quedará determinado por la libertad. Pero por una libertad que no opera antojadizamente y sin fundamento, sino que es realización de condiciones que se le regalan en la historia.

Pero, justamente, porque no se verifica una relación lineal que va del pasado al futuro, pasando por el presente, la historia se muestra en su estructura ontológica como una realidad en la que el futuro no solo está condicionado por el presente, sino que -inversamente- también este presente histórico está determinado por el futuro. Antes de acontecer en el tiempo, el futuro hace sentir su presencia en el presente y lo determina

«In der Gegenwart gründet die Gewesenheit als ein künftige. Was wir jetzt sind, legt fest, was wir gewesen sein werden» (B. WeLTE, Geschichtlichkeit als Grundbestimmung..., GS I/2, 167-168). 
internamente, permitiéndonos reconocerlo como aquello habrá sido. En este sentido, el futuro está más en el presente que en el porvenir. Su realidad futura nos es del todo desconocida. Ni siquiera sabemos si será. Sin embargo, él nos importa ahora: nos inquieta, nos angustia, nos llena de esperanza.

La importancia del futuro en la ontología de la historia propuesta por Welte salta a la vista. Pero de nuevo se trata de una importancia que es correlativa al presente y al pasado histórico. No hay una determinación aislada del futuro, sino que, justamente cómo este se constituye en el presente y para el presente, remitiendo de nuevo la cuestión del significado y del fundamento al ejercicio mismo de la libertad. El apremio de la historia está en que es en el presente donde se generan las posibilidades de significación y fundamento futuro de la existencia presente-personal, social, global... Y aunque ese futuro no exista aún y, quizás, nunca llegue a existir, quedamos absolutamente remitidos a su posible novedad.

\section{El carácter personal de la bistoria}

Ahora bien, hasta aquí, la ontología de la historia propuesta por Welte pudiera parecer una cuestión meramente abstracta, carente de un sujeto real: las determinaciones de pasado-presente-futuro en la dinámica del despojamiento y la conservación; la afirmación de su irrepetibilidad, etc. Sin embargo, si observamos más detenidamente, en cada una de esas determinaciones formales se nos ha manifestado una realidad que las supera, alcanzando en ella toda su consistencia y sentido: la libertad. La historia solo adquiere consistencia ontológica cuando es vivida como ejercicio de la libertad personal. Los bruta facta se hacen historia cuando hay hombres y mujeres que pueden reconocerlos, comprenderlos, atestiguarlos. Hasta entonces, hasta que ello no sucede, simplemente no son, no hay historia. Por ello, un momento decisivo de la ontología de la historia que propone Welte, está dado por el carácter personal que le reconoce a ella, llegando incluso a afirmar que «toda historia tiene un fundamento personal que le es esencialmente necesario» ${ }^{37}$.

En el contexto de esta ontología de la historia, Welte caracteriza el concepto de persona como un Bei-sich-sein, como ser/estar-consigo-mismo y, de este modo, ella es algo para sí misma, es decir, adquiere identidad, es-sí-misma ${ }^{38}$. El ser-consigo-mismo no se alcanza por un proceso de en-

37 B. WeLte, Geschichtlichkeit als Grundbestimmung..., GS I/2, 178.

38 Cf. B. Welte, Gescbicbtlichkeit als Grundbestimmung..., GS I/2, 179. 
simismamiento, sino que en el ser interiormente sí-mismo. Dicho de otro modo, la mismidad no se constituye desde un movimiento que iría desde fuera del sujeto hacia su interior, sino que desde el ser-consigo-mismo en una apertura radical a todo cuanto es. En esta apertura al ser, que aquí Welte llama universal y trascendente ${ }^{39}$, ser-consigo-mismo es ser-con-otrosen-el-mundo ${ }^{40}$. La persona no solo se realiza como sí-misma en cuanto se reconoce como realidad para sí misma, sino también porque es capaz de reconocer la realidad de todo cuanto es no como mera exterioridad, sino como en-sí-mismo. La persona es/está-consigo-misma en esta apertura y relación a sí-misma y a todo cuanto es. En este ser-consigo-misma en relación se constituye la originalidad irreductible de toda persona, de tal modo que «nadie puede ser lo que ella es» ${ }^{41}$. En su ser-consigo-mismo, por tanto, la persona nunca podrá ser reducida a las relaciones funcionales, utilitarias y hasta abusivas, a las cuales muchas veces es sometida. El ser/ estar-consigo-mismo -aunque muchas veces desfigurado, gracias a sí mismo o a otros- permanece siempre irreductible a todo intento de dominio y poder. En cualquier circunstancia, ser-sí-mismo es posible. Incluso en la situación más extrema de alienación, en la que el sujeto no se posee, ni vive desde desde-sí-mismo, es posible reconocer una identidad personal, un sí-mismo, aunque enajenado. La alienación o enajenación es predicado de un ser-consigo-mismo, es la situación en la que puede encontrarse una persona, pero respecto de la cual esta siempre podrá preguntarse críticamente, reconociéndola como lo otro del estar-consigo-mismo, incluso como su opuesto, como el estar/ser-fuera-de-sí-mismo.

En la perspectiva de esta afirmación del carácter personal de la historia de la libertad, me parece que podemos volver a escuchar a M. Blondel, quien de modo semejante a Welte también intentó una superación del idealismo trascendental kantiano -el que consideraba como un «realismo al revés»-, postulando la subjetividad como un «principio interno de unidad», un «centro de agrupamiento imperceptible», una «operación inmanente», una «acción original» ${ }^{42}$. La subjetividad es capaz de encontrar la unidad en la multiplicidad, como asimismo la multiplicidad en la unidad. Por ello, propiamente, se trata de la «unidad de una síntesis», y no, sin más, de una unidad establecida solo desde el sujeto o del objeto. En la perspectiva de su tesis latina sobre el vinculum substantiale en la filosofía de

\footnotetext{
39 Cf. B. WeLte, Geschichtlichkeit als Grundbestimmung..., GS I/2, 178 y ss.

40 Cf. B. Welte, Geschichtlichkeit als Grundbestimmung..., GS I/2, 246 y ss.

$41 \quad$ B. WeLte, Geschicbtlichkeit als Grundbestimmung..., GS I/2, 182.

42 M. Blondel, La acción..., 119.
} 
Leibniz, postula que «la unidad de una síntesis no consiste sino en una relación interna de partes; es la proyección ideal del conjunto en un centro de percepción. El vinculum es de naturaleza inteligible y, hablando con propiedad, subjetiva» ${ }^{43}$.

En continuidad con esta ontología de la historia, Welte da otro paso fundamental, cual es el de situar este Bei-sich-sein en el horizonte de la pregunta por el sentido de la historia, de que esta en definitiva sea algo. Para ello, habría que convenir en que la persona no es un ser-consigo-mismo neutral en la amplitud trascendente y universal de su existencia, sino que vive llena de interés en las realizaciones concretas de su existencia: pensando, amando, sufriendo, jugando, etc. Una apertura del ser que fuera simple indiferencia respecto de sus realizaciones posibles no sería constitutiva de la persona, «ni la historia -agrega Welte- se pondría en movimiento» ${ }^{44}$. El dinamismo mismo de la historia no solo está sostenido formalmente por la persona y por el ejercicio de su libertad, sino que realmente, por cuanto ser persona es actualización de las posibilidades de ser-con-otros-en-elmundo, es habitar el «espacio abierto de experiencias» ${ }^{45}$, es la constante búsqueda por alcanzar aquello que mueve y configura la existencia.

\section{Los desafíos de la historia a la teología}

\section{La comprensión del carácter histórico de la teología}

De modo general Welte recuerda la doctrina del Aquinate, particularmente aquella sentencia de la Summa contra gentiles en la que afirma: «intellectus in actu, et intelligibile in actu, sunt unums ${ }^{46}$. Esta afirmación le sirve a Welte para expresar la mutua referencia entre el conocer y aquello que es conocido. La cosa conocida no es un mero objeto para quien conoce, sino que se constituye en el mismo acto del conocer. Del mismo modo, el conocer no acontece si no in actu, en referencia al objeto que se le manifiesta para ser conocido. Dicho de manera muy simple: no hay conocimiento sin objeto, no hay objeto sin conocimiento. Ahora bien, a esta primera correspondencia Welte agrega una segunda: la que se establece entre conocer y ser. En efecto, en el conocer se despliega aquello que somos, de tal modo que

\footnotetext{
43 M. BlONDEL, La acción..., 120-121.

44 B. Welte, Geschichtlichkeit und Offenbarung, 184.

45 B. WeLte, Filosofía de la religión..., 51.

46 Tomás de Aquino, Summa contra gentiles, II c. 55 n. 11 y II c. 59 n. 13. Cf. B. Welte, Geschichtlichkeit als Grundbestimmung..., GS I/2, 138.
} 
el acto de conocer no queda solo referido a una cosa, a un objeto, sino que el mismo es un «acto de ser» nosotros mismos, como despliegue de toda nuestra vitalidad. Por ello -concluye Welte- todo conocer -y en él todo lo que es conocido- nos remite a nuestro propio modo de ser y, por tanto, a nuestro acontecer histórico.

De allí que la teología, como conocimiento que nace de la fe, sea un momento del acontecer histórico del pensar. La relación entre historia y teología, en la perspectiva de Welte, acontece en el pensar, en el entender, en el comprender (Verstehen). No hay revelación allí donde no hay comprensión: «revelar está necesariamente orientado al comprender» ${ }^{47}$.

Es así que historia y teología se requieren mutuamente. La historia no es un conjunto de datos, cifras, sucesos. Al menos nos preguntamos si ellos no son algo más que eso. Y en esa pregunta se nos muestra la posibilidad de que la historia tenga algún sentido, que en ella se nos manifieste la divinidad, que se nos muestre la cercanía trascendente de Dios. Estamos a diario buscando concatenar los hechos, correlacionarlos unos a otros, a fin de alcanzar una comprensión global de lo que sucede. Las causalidades pueden ser de orden físico, psíquico, económico, político, religioso, entre otras, pero pareciera que nos resistimos a aceptar que lo que sucede, simplemente sucede; que lo que es, simplemente es. Pareciera difícil pensar sin preguntarse por el sentido del pensar y de aquello que pensamos.

\section{La comprensión del carácter teológico de la bistoria}

Para Welte, la historicidad es esencial (wesentlich) al cristianismo. Por ello, la falta de comprensión de la historia y del campo semántico que le es propio, conlleva -necesariamente- a la incomprensión del mismo cristianismo ${ }^{48}$. De allí que la relación entre historia y teología no sea optativa, la comprensión teológica si quiere realmente alcanzar su objeto, entonces ella requiere ser, también, comprensión de la historia.

A diferencia de estructuras de pensamiento como el griego o el religioso musulmán, para el cristianismo no hay discontinuidad entre acontecimiento histórico y verdad. Sócrates, por ejemplo, consideraba que las circunstancias históricas en el descubrimiento de la verdad -entre ellas, el mismo Maestro- perdían consistencia al momento de encontrarse con ella. Algo semejante habría expresado Mohamed, cuando afirmó: quien reza a Mohamed, lo sabe: Mohamed ha muerto. Sin embargo, quien reza

47 B. WeLte, Geschichtlichkeit als Grundbestimmung..., GS I/2, 136.

48 Cf. B. WeLte, Geschichtlichkeit als Grundbestimmung..., GS I/2, 137. 
a Dios sabe que Él vivirá para siempre, que nunca morirá. Para Sócrates o Mohamed las circunstancias históricas en las que acontece la verdad, aunque importantes, son pasajeras, efímeras ${ }^{49}$. En cambio, para el judeocristianismo la historia no es accidental o tangencial a la verdad que en ella acontece. El Maestro no es separable de su enseñanza. La verdad cristiana no es un en-sí ahistórico, un conjunto de afirmaciones sustraídas del suelo en que nacieron y germinaron, desligadas de la comunidad que ha dado testimonio con su vida de su carácter salvífico. La verdad es Cristo y Cristo es la Verdad. La celebración pascual es uno de los testimonios más elocuentes de cómo Jesús de Nazareth no es el «Jesús histórico no más», de cómo toda la salvación -en el despliegue de todo tiempo y espacio- ha acontecido en un solo instante de la historia, quedando indisolublemente asociada a ella, de cómo esta historia da sentido a toda historia.

Por cierto, la comprensión de Jesús de Nazareth como cumplimiento y plenitud de las promesas de Dios, implicaba un cambio muy profundo en la comprensión filosófica y religiosa de la historia. Según Welte, el pensamiento cristiano iría tomando progresiva conciencia de su carácter esencialmente histórico, siendo Agustín un impulso decisivo para ello. En efecto, no se trataba solo de reconocer la universalidad de la salvación de Dios en la historia de Jesús de Nazareth, sino que en ese reconocimiento comprender que era la misma historia la que adquiría densidad teológica. Pero no solo la historia, o esa historia, la de Jesús, sino que también la propia existencia humana. En particular, en los libros VII y VIII de sus Confesiones, Agustín expresa la transición desde una espiritualidad plotinista, según la cual la luz eterna de la verdad divina se irradia sobre el alma sin consideración alguna de la historia, a una espiritualidad cristiana, que nace como respuesta creyente a la manifestación de Cristo en la historia ${ }^{50}$. En Cristo, el tiempo alcanza una densidad nueva: el tiempo ya no queda subsumido en la generalidad de una idea, o en la representación arquetípica de un mito, sino que, en su unidad, queda asociado a la redención plena y definitiva de Dios en Cristo, quien ha sido constituido por el Padre en principio y fin de todo tiempo, quien por su Espíritu reúne a todos los pueblos en la ciudad de Dios.

Esta referencia del tiempo a Cristo, a un acontecimiento particular en el tiempo, tiene una doble consecuencia: por una parte los hechos históricos dejan de ser comprendidos como hechos particulares, sin conexión entre sí, como sucesos meramente yuxtapuestos en la cadena sin fin de la

49 Cf. B. WeLte, Geschichtlichkeit als Grundbestimmung..., GS I/2, 141-143.

50 Cf. B. WeLte, Geschichtlichkeit als Grundbestimmung..., GS I/2, 144. 
historia; pero, por otra, esa unidad deja de ser una unidad indeterminada, abstracta y absoluta, en la cual se disuelve todo tiempo, hecho, acontecimiento. $\mathrm{Al}$ asociar todo tiempo a Cristo, esta totalidad adquiere un carácter personal, que no solo funda la unidad de la historia, sino que también - por su mismo carácter personal- sostiene también toda particularidad, toda individualidad, toda singularidad.

Al entrar en contacto con el pensamiento hegemónico de su tiempo, especialmente con las categorías filosóficas griegas de la antigüedad, se producirá una alteración importante tanto en la misma cultura griega como en el cristianismo. Para el pensamiento antiguo, la historia no era una categoría relevante o significativa; progresivamente, el cristianismo colocaría todo acontecer en relación a una historia particular: la de Jesús de Nazareth. Por su parte, al entrar en contacto con la antigüedad, el cristianismo aspirará a ser él también sabiduría, modificaría sus propias conceptualizaciones, integraría nuevas estructuras de pensamiento ${ }^{51}$.

En su afán por elaborar una teoría del anuncio de la salvación, el pensamiento cristiano comenzará a utilizar categoría metafísicas, que le posibilitarán ir validándose en la cultura helénica; pero, al mismo tiempo, esta inculturación -históricamente necesaria- representaba un desplazamiento en la perspectiva, intereses y acentos: desde una conciencia teológica marcada por la historicidad del acontecimiento de la salvación a una elaboración teológica determinada por preguntas con escasa raigambre histórica. Según Welte, «la revolución agustiniana de la conciencia histórica no pudo conducir a una construcción teórica adecuada» ${ }^{52}$.

Cuando el Concilio Vaticano II planteó el deber de «escrutar a fondo los signos de los tiempos e interpretarlos a la luz del Evangelio» ${ }^{53}$, no hizo sino recordar una antigua deuda de la teología $a^{54}$ : la de ser una inteligencia de la fe en el tiempo. Pensar a Dios, es pensarlo en el tiempo, en las condiciones y posibilidades maravillosas que él nos ofrece, pero también en el

51 Cf. B. WeLte, Geschichtlichkeit als Grundbestimmung..., GS I/2, 146 y ss.

B. WeLte, Geschichtlichkeit als Grundbestimmung..., GS I/2, 147.

53 Gaudium et Spes, n. 4.

54 Sobre el camino que al respecto ha recorrido la teología desde la antigüedad hasta nuestros días ya he escrito en mi libro La verdadera religión, pp. 40-70. Sobre lo acuciante que esta tarea se ha vuelto hoy, véase mi artículo ya citado «Den Glauben in der Konkretheit der Geschichte Denken. Bernhard Weltes Beiträge zur Theologie», en M. Eckholt (Ed.), "Clash of civilizations" - oder Begegnung der Kulturen aus dem Geist des Evangeliums?. Bernbard Weltes Impulse für den interkulturellen Dialog mit Lateinamerika (Lit, Berlin 2009), 51-67. 
ocultamiento que supone. Es la misma historia la que desde sí requiere inteligencia teológica, discernimiento de la presencia del Espíritu en medio de ella, inserción de toda ella en el acontecimiento histórico-escatológico de la salvación de Dios en Cristo.

\section{La teología como memoria histórica del acontecer de la Verdad}

Una teología de la historia debe tener como paradigma fundante y constitutivo la teología de la historia por excelencia: la historia de Jesús de $\mathrm{Na}$ zareth. Nuestra teología no se validará como histórica por asumir todos los instrumentales análiticos que ofrecen las ciencias humanas y sociales, ni tampoco porque asume las preguntas y cuestiones que emanan de la comprensión filosófica de la historia, menos aún porque se orienta a resolver problemas que tienen urgencia histórica. Por cierto, la teología deberá acometer estas y otras tareas. Pero ella tiene como referencia fundamental de toda tarea la historia de Jesús de Nazareth, a quien debiéramos reconocer como único Señor y Maestro.

No se trata de establecer un principio cristológico de interpretación de la historia al margen de toda comprensión humana. Por el contrario, se trata de mirar, también, cómo en las comprensiones que vamos teniendo de la historia se dice o contradice la historia de Jesús. La teología de la historia es, primera y fundamentalmente, teología de un historia particular: la de Jesús de Nazareth y de la comunidad que creyó en Él. Desde esta historia accedemos al sentido trinitario de ella, desde esta historia reconocemos el compromiso de Dios con la historia de todos los hombres y de los pueblos; desde esta historia comprendemos y celebramos que la historia no es sucesión lineal de hechos, sino acontecimiento de libertad y de gracia.

Como teología de la historia de Jesús de Nazareth, la teología aspira a ser testimonio siempre actual del acontecer de la verdad. En efecto, para Welte la verdad de la fe tiene el carácter de acontecimiento: es «aquello que sucedió y que sucede, en cuanto acontece como verdad. Esta verdad acontece, en cuanto ella surge desde su propio origen divino y resplandece, iluminando a quien ella alcanza y a quien la acogee ${ }^{55}$.

De este modo la verdad deja ser una abstracción, queda asociada a una historia que constituye y conforma internamente. Ciertamente, escribe Welte, descartando cualquier tipo de relativismo, «tenemos razones para

55 B. Welte, «Über den Sinn von Wahrheit im Bereich des Glaubens» en: Zeit und Geheimnis, 287. 
pensar que en último término hay una sola verdad que todo lo comprende. Sin embargo, desde el momento en que esa verdad es comprendida bajo determinados respectos en ideas, conceptos y palabras, es decir, cuando ella se hace lenguaje, entonces ella aparece en una diversidad de posibilidades y surge el problema de la verdad e historicidad $\diamond^{56}$. Pero, más aún, en su misma historicidad, la verdad de la fe es un acontecimiento personal: es el acontecimiento de Jesús de Nazareth, que acontece en un tiempo y en un lugar determinados, y que, aconteciendo para siempre, es manifestación y testimonio del ser de Dios, es luz para los hombres, es vida entregada, es libertad. Por ello, "en la Biblia se habla menos de lo que es, y, mucho más, se cuenta y se anuncia.

\section{La teología como memoria de la cruz.}

Si la teología queda asociada al acontecer histórico de la verdad, entonces ella deberá ser capaz de decir cómo efectivamente toda negación queda contenida en la vida y el ser. Bajo este respecto, una teología que no sea teología crucis, no se verifica como teología cristiana. Y no de una cruz estilizada, formalizada, banalizada, sino de una cruz según esta es vivida, cargada y sufrida por los hombres y mujeres de cada tiempo. Por ello, tampoco se trata de una especulación espiritualista respecto de la cruz, sino de cómo ella hoy, por la gracia del Espíritu, está siendo contenida en la historia única de la salvación de Dios en Cristo. Allí la teología tiene una función ineludible, especialmente en un contexto en donde la felicidad que se busca huye de todo sacrificio, de toda renuncia y despojamiento; donde la felicidad que buscamos no es capaz de conservar más que la levedad del ser; donde la felicidad que deseamos muchas veces nos lleva a huir de la historia y del mundo. Si la teología no es capaz de contener en su propio pensamiento esta historia y este mundo, o si se quiere este mundo en su historicidad real, no solo deseada, entonces ella no estará siendo una teología auténticamente creyente del Dios de la historia, afirmará más sus propias comprensiones del ser que aquellas que aquellas que nacen del discernimiento en el Espíritu de Dios, según enseña el libro de la Sabiduría:

56 B. WeLte, «Die philosophisch-theologische Problematik», en: Herderkorrespondenz 34 (1980) 77. 
«¿Quién comprende lo que Dios quiere?

¿Qué hombre conoce el designio de Dios?

¿Quién comprende lo que Dios quiere?

Los pensamientos de los mortales son mezquinos,

y nuestros razonamientos son falibles [...]

Apenas conocemos las cosas terrenas

y con trabajo encontramos lo que está a mano:

pues, ¿quién rastreará las cosas del cielo?

¿Quién conocerá tu designio,

si tú no le das sabiduría,

enviando tu Santo Espíritu desde el cielo?» (Sab 9, 13-18).

La teología, por tanto, por su carácter histórico, también habrá de vérselas con su precariedad. Ella se puede verificar como theologia temporis, pero justamente en ello muestra el estar siempre en tensión hacia una comprensión más honda del propio tiempo, puesto que en él ha querido habitar el misterio infinito de Dios.

La teología cristiana de la historia se encuentra ante el desafío de ser teología de la cruz por cuanto tendrá que pensar desde ella la negación de toda historia. Pero desde Cristo, la teología de la cruz no es solo la referencia formal a un principio dialéctico de la historia, sino que acontecimiento desgarrador del amor hasta el extremo (cf. Jn 13, 1). Es así que la teología de la cruz se transforma en theologia amoris, de un amor llevado hasta las últimas consecuencias, sellado con la entrega de sí mismo hasta la muerte. De este modo, el lógos teológico queda remitido a un lógos que solo parcialmente tiene que ver con ideas, teorías, conceptos; o, si se quiere, en la revelación de Dios en Cristo, se trata de «hechos y palabras intrínsecamente conexos entre sí, de forma que las obras realizadas por Dios en la historia de la salvación manifiestan y confirman la doctrina y los hechos significados por las palabras, y las palabras, por su parte, proclaman las obras y esclarecen el misterio contenido en ellas» (DV 2). El Lógos de Dios se ha hecho carne; Jesús de Nazareth es el teológos por excelencia; por tanto, toda theología queda desde entonces remitida a los hechos y palabras en los que acontece la autocomunicación de Dios a los hombres. Es así que la teología de cruz, como teología en el Lógos de Dios, no es solo teología 
del mysterium iniquitatis, sino que, más radicalmente, del amor que allí se manifiesta para salvar de toda injusticia, de toda mentira y de toda muerte.

La prueba de la verdad no está, por tanto, en la formalidad de un silogismo lógico bien construido, sino que en el amor salvífico y liberador de Dios. Así lo atestigua Moisés cuando quiere demostrar al pueblo que sus obras son testimonio de que él es enviado del Dios «que hace algo enteramente nuevo» (Num 16, 30); o también Josué, cuando de modo semejante a Moisés (Jos 3, 7), es reconocido como enviado del Señor por el testimonio que él da de los hechos liberadores de Dios con su pueblo (Jos 3, 10); y, por cierto, Jesús, cuando -por ejemplo- le dice a sus amigos: «En esto conocerán todos que son mis discípulos, si se tienen amor los unos a los otros» (Jn 13, 35). La verdad del discipulado y de la misión no se constituye, primera ni principalmente, por el estatus de las personas en el ordenamiento jurídico-eclesiástico, ni tampoco por la lejanía o cercanía de estas a los objetos, espacios o acciones sagradas. La verdad de los enunciados teológicos tampoco se verifica por su sola consistencia lógica, por la sola continuidad formal con la tradición que los soporta, y menos aun por el simple reconocimiento eclesial o social de quien los pronuncia. La verdad de la cual trata la teología remite a esos hechos y palabras intrínsecamente conexos. Y, como sabemos, especialmente a los hechos. Incluso pudieran faltar las palabras: un hecho vale más que mil palabras, dice la sabiduría popular.

Con Job nos hemos preguntado muchas veces: «iNo hay fin a las palabras vacías?» (Job 16, 3). Constatamos una y otra vez, en nuestra propia vida, una distancia entre los hechos y las palabras. Nuestras palabras, a diferencia de las de Moisés, Josué o Jesús, pocas veces remiten a hechos efectivamente liberadores. Y sabemos, Jesús nos lo dijo: «No todo el que me dice: "Señor, Señor", entrará en el reino de los cielos, sino el que hace la voluntad de mi Padre que está en los cielos» (Mt 7, 21). No se trata aquí de una parénesis, ni siquiera de una parénesis teológica, por legítima que esta sea. Lo que está en cuestión es cómo la teología es testimonio lúcido, inteligente, crítico de la acción salvífica de Dios en la historia, del amor vivido hasta el extremo, de la vida según el Espíritu de Cristo. La historia, según lo dicho, lo posibilita todo, pero también lo arrebata todo. Ella contiene y despoja al mismo tiempo. De allí que la teología sea invitada a ser testigo de la permanencia regalada del amor: «El mundo pasa, y también sus pasiones, pero el que hace la voluntad de Dios permanece para siempre» $(1 \mathrm{Jn} 2,17)$. No se trata de una afirmación tenaz y voluntariosa del tiempo, sino de la vida que ha vencido la muerte. 


\section{La teología de la historia como teología de la libertad}

Como teología de la historia, la teología no puede sino ser, también, teología de la libertad. En efecto, según hemos visto, cada tiempo de la historia -pasado, presente y futuro- y la historia como entrecruzamiento dinámico de los tiempos no acontece sin la libertad del hombre. Hablar de carácter histórico del hombre y de la mujer es hablar de su constitución para la libertad, es hablar de que la significación del tiempo nunca acontece sin él, es reconocer que tanto las dinámicas de despojamiento como de conservación del ser en la historia son siempre interpelación a la propia acción.

Como teología de libertad, la teología no solo se deberá preocupar por las condiciones estructurales que favorezcan su ejercicio -condiciones políticas, económicas, jurídicas, etc.- sino que sobre todo deberá preguntar por el carácter personal de esta historia de la libertad. Si es la persona la que otorga a la historia su sentido -reconociéndola, agradeciéndola, atestiguándola, etc.- entonces habrá que pensar cuáles son las condiciones y posibilidades de actualización de la persona en la historia. Dicho aquí de otro modo: la teología deberá esclarecer cómo la acción salvífica de Dios constituye a la persona como sujeto libre como, ser-consigo-mismo en apertura al ser de todo cuanto es. Esta tarea me parece hoy particularmente urgente, especialmente al considerar la fuerza de los procesos de funcionalización, homogenización y nivelación de los que formamos parte, siendo nosotros mismos sujetos protagónicos en ellos. Ser sujeto autónomo y libre sigue siendo muchas veces un despropósito, un riesgo para el sistema, un peligro para el orden vigente. Para muchos, ser Iglesia y ejercer la libertad parecen irreconciliables. Y este parecer tiene motivos cuando el sistema institucional no contribuye al desarrollo de hombres y mujeres libres, capaces de pensar y actuar por sí mismo, invitándolos a ejercer su libertad y responsabilidad. Si la teología no ayuda al reconocimiento y configuración de la persona en su dignidad y libertad, entonces no solo estará perdiendo la ocasión de verificarse como teología de la historia, sino que, simplemente, ella dejará de ser teología, de hablar con sentido del Dios que no ha querido un pueblo de esclavos sino de amigos (cf. Ex 33, 11; 2 Cro 20, 7; Is 41, 8; Jn 15, 15).

El carácter personal de esta historia de la libertad y, justamente por ser auténticamente personal, es también social y comunitario. En la propuesta ontológica de Welte la afirmación de la persona en su dignidad, originalidad e irrepetibilidad no está asociada a una reivindicación del sujeto individual contra, o al margen, de su ser social, si no que por el contrario 
es establecida como condición del ser-sí-mismo en relación a otros. De allí que para la teología de la historia se abre un desafío particularmente acuciante, por cuanto más o menos explícitamente vivimos un tiempo de exacerbación del individualismo. En este contexto, la teología podrá esclarecer que el ser-consigo-mismo no solo se verifica como relación con otros, sino que es en Cristo donde este ser del hombre es llevado a plenitud, por cuanto en Él la salvación acontece como participación en la comunión trinitaria. Dios invita al hombre a salir de sí, no para enajenarse, sino para ser más plenamente sí-mismo en el encuentro y la comunión. Por ello, la teología deberá ser memoria de que «fue voluntad de Dios el santificar y salvar a los hombres, no aisladamente, sin conexión alguna de unos con otros, sino constituyendo un pueblo, que le confesara en verdad y le sirviera santamentes ${ }^{57}$ (LG, 9). En la perspectiva de la fe, la autonomía y la libertad se realizan cuando llegamos a ser en Cristo; o, dicho de otro modo, Cristo es quien haciéndonos partícipe de su condición de Hijo, nos hace ser plenamente nosotros mismos en la comunión con Dios y con todo el género humano.

\section{Conclusión}

Ciertamente, el enfoque de Welte para abordar la cuestión de la historia es principalmente de carácter filosófico: es decir, busca esclarecer por medio del pensamiento aquello que es la historia, reconociendo el carácter histórico de todo acontecer humano. Pero justamente porque todo lo auténticamente humano acontece como historia, entonces la teología también queda incorporada en la dinámica de la historia. El objeto de la teología, Dios y su revelación en Cristo, no la eximen de su historicidad. Sin embargo, en lugar de que esto sea una condena a la finitud, a la inmanencia, a la evanescencia, es justamente Dios, y su autocomunicación, quien permite a la teología reconocer tanto su verdadero sentido histórico como su verdadero sentido trascendente. En efecto, en su revelación, Dios se nos manifiesta como Señor del tiempo, como alfa y omega, como principio y consumación del tiempo. Dios no se establece como una eternidad inmutable fuera del tiempo, sino como Creador y Señor de la historia; en la precariedad de todo acontecer manifiesta la grandeza de su amor; en el imperio de la muerte hace resplandecer la fuerza de la vida sin fin.

Es el reconocimiento de este carácter trascendental de la historia lo que permite a Welte elaborar un pensamiento filosófico que directamente

57 Lumen gentium, 9; cf. LG 4. 
se pregunta por el significado de la historia para el quehacer teológico, por las implicancias que tiene para la teología el reconocimiento de la historicidad del pensamiento y, a su vez, por las perspectivas y preguntas que la misma teología hace a la filosofía de la historia. De este modo, por tanto, en Welte no solo encontramos un pensamiento filosófico que indaga sobre las condiciones y posibilidades de la historia, sino que también con un pensamiento que expresamente aborda la pregunta por el carácter teológico del acontecer histórico. No se trata de otra pregunta: de una pregunta teológica añadida o sobrepuesta a la pregunta filosófica. En la misma y única pregunta por la historia se manifiesta un sentido teológico latente que es necesario escudriñar y articular por medio del pensamiento y del lenguaje. 
Resumen: En este artículo se muestra cómo la ontología de la historia propuesta por Welte, ofrece una comprensión de la historia en que esta se constituye en una apertura radical del tiempo, donde presente-pasado-futuro no se comportan como unidades fijas y sucesivas, sino que se trascienden a ellas mismas en relaciones de inclusividad y de mutuo requerimiento. Al mismo tiempo, se indica que esta historia no se constituye al margen del sujeto personal y social, sino que está posibilitada por el ejercicio mismo de la libertad y de la acción, siendo así ella misma una ontología de la libertad. Así, se propone reconocer la historia como aquello que es irreductible, indescifrable, inabarcable, como aquello que siempre supera los márgenes estrechos a los que se la quiere reducir.

Desde esta ontología de la historia propuesta por Welte, es posible reconocer lo teológico com una posibilidad latente a la misma historia. Posibilidad, por cuanto no existimos en el reino de la mera determinación, sino que de la libertad. En la historia, en el dinamismo del tiempo, podemos reconocer la presencia trascendente de Dios: una presencia, sin embargo, que no se deja atrapar; una presencia que rompe todo cerco de poder; una presencia que es siempre interpelación a la libertad.

Palabras clave: Bernhard Welte; Historia; Teología de la historia

Abstract: This article shows how the ontology of history proposed by Welte offers an understanding of history where history is constituted within a radical time opening, where present-past-future do not behave as fixed successive units, but rather are transcended in relationships of inclusiveness and mutual dependency. At the same time, it is noted that this history is not constituted outside of the margin of the personal and social subject, but is made possible by the very exercise of freedom and action, history itself being an ontology of freedom. Thus, we propose recognizing history as that which is irreducible, indecipherable, and unable to be completely encompassed, as that which always exceeds the narrow margins to which it is usually intended to be reduced.

From the ontology of history proposed by Welte, it is possible to acknowledge the theological as a latent possibility of history (possibility, inasmuch as we do not exist in the realm of mere determination, but of freedom). In history, and the dynamism of time, we can recognize the transcendent presence of God, a presence, however, that is not trapped, a presence that breaks all fences of power, a presence that is always questioning freedom.

Keywords: Bernhard Welte; History; Theology of history 